10. I en psykoanalytisk sammenhæng, har forholdet mellem film og drom varet genstand for betydelig opmaxsomhed i den diskursive retning, dex er grundlagt af Lacan og Metz, mest fremtradende $i$ The Imaginary Signifier. Stadig inden for den psykoanalytiske sammenhang, men afvigende fxa Metz pä vigtige punkter, er Robert Eberwein's Film and the Dream Screen (Princeton Univ. Press, 1984), og Gay Lynn Studlax's Visual Pleasure and the Masochistic. Aesthetic: The Von Sternberg/Dietrich Paxamount Cycle, upubl. afhandling, USC, 1984 (et uddrag herfra vil forekomme i Volume II af Movies and Methods, red. af Bill Nichols, v. of Calif. Press). Vlada Petridts Film and Dreams: An Approach to Bergaan ex en samling essays, hvoraf nogle (inklusive Petric's arbejder og mine) trækkex pä neurobiologiske modelier. Dette perspektiv er ogsa reprasenteret i flexe essays (inklusive nogle af Petric, Hobson, Durgnat, Kawirn og mig), som stär i Dreamworks, et tvarfagligt kvartalsskrift on forholdet mellem drom og kunst.

11. De to hovedvarker on dette emne er Peter H. Woods's "Television as Dream" $i$ Television: The Critical View, red. af Horace Newcomb (New York: Oxford university Press, 1979), pP. 517-535, og "Reality and Television: an Interview with Dr. Edmund Carpenter", Television Quarterly, X, 1 (efterâr 1972), pp. 42-46. Varker som har forsфgt en trestrenget sammentigning, fokuserer som regel på biograftilm på bekogtning af fjernsyn, idet de havder, at sammerligningen mellem film og drome ex mere interessant (se Raymond Durgnat, "The Hunting of the Dream-Snark", Dreamworks, II, 1, efterar 1981, pp. 76-82) eller mere frugtbar i udviklingen af formelle ligheder (se vlada Petric's "A Theoretical-Historical Survey: Film and Dreams", 1 Film and Dreams, pp. 1-48).

12. Hobson, "Film and the Physiology of Dreaming sleep", p. 14.

13. Ibia., p. 23.

14. Petric, "A Theoretical-Historical Survey", p. 23.

15. Hobson, ibia, P. 24.

16. Ibi.a., pp. 23-24.

17. For en fremragende analyse af, hvad filmen afslorer on fjernsyn, se Berverle Houstons's "King of Comedy: A Crisis of Substitution", Framework, 24 fforar 1984), pP. 74--92.

Marsha kinders artikel bringes i Mediekultur efter aftale med forfatteren, under forudsatning af at vi oplyser folgende:

(C) 1984 by The Regents of the University of California. Repxinted from EILM QUARTERLY, Vol 38, No. 1, Fal1 1984, pp. 2-15, by permission of The Regents. Subscriptions to EILM QUARTERLY are avalable from: The University of California Press, 2120 Berkeley Way, Berkeley, California, 94720, USA, for $\$ 11$ per year for individuals, $\$ 19$ for institutions. Add $\$ 3$ per year for foreign postage.

Marsha Kinder er associate professor ved The Critical studies Program, The School of Cinema-Television, University of southern California, Los Angeles. 


\section{En musikvideo er ikke bare en musikvideo}

\section{Af Karin Jacobsen}

Mange unge ex storkonsumenter af Levende bitheder. Huad far de ud af de mange bitheder? F.eks, af muskvideoeme? Hvordan far man struktureret et undervisuthoforlob i denne nye genre? og hvordan far man retateret musikvideoeme histowisk og estetisk?

Det giver Karin Jaeobsen sit bud pa.

De unges medieforbrug andres ofte - og oftest til et merforbrug. Det hax varet min erfaring, at dette ikke helt hax varet tilfaldet med musikvideoer.

I efteraret 85 havde jeg lant et promotionbånd med nye musikvideoer. Der var mange i mine filmklasser, der var interesserede i at overspille bandet. Et ås tid efter kommer jeg med samme entusiasme og foreslar et forlob 1 musikvideoer. Dette forslag blev nasten pebet ud. Nyhedens interesse er tydeligvis gatet af musikvideoer. Flere elever har tillige mulighed for at se helt nye videoer via satelitprogramerne. Hit'ene endres konstant, og eleverne vil helst se helt nye videoer ellex "flotte klassikere" som f.eks. Peter Gabriels Sledgehammer.

Eleverne brugex dagligt musikvideoerne som musiktapet, og af den grund vil de helst se kunstneriske film og TV, nar de skal arbejde med det. 
Der var, i mine klasser, saledes ikke basis for et forlob udelukkende i musikvideoer. I det forlob jeg senere beskriver, er musikvideoer dog representeret med en stor andel.

Der er stor forskel i unge og voksnes made at konsumere billeder på. De unge har tydeligvis en langt storre billedhukommelse end de voksne, hvilket naturligvis ex begrundet i, at de forstnavnte er opdraget med billeder. Trods denne store forstalelse for billeder ex mange unge mennesker blot konsumenter og billednydere. Dette kan tydeligt ses af fplgende citat fra Levende bille-

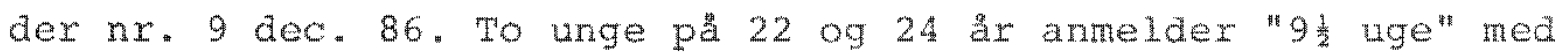
denne konkiusion:
Vi er en ny generation af biografgangere, der ex vokset op ned hi-tech, reklamer, video og amerikanske film. Vi ex tratte af jeres postulater om, at det har fordarvet vores astetik-, moral-og kvalitetsbegreber. Vi kan godt tanke selv. Og prøv så at gå i biografen og se "9u uge", men lag jeres sadvanlige forsvarsparader på hylden denne ene gang. "9l uge" skal ses, fples og bolles ud af kroppen. (Tina Tjpmholt, Svend Rasrassen?.

At domme efter ovenstaende citat ex de unges interesse i billedmedierne udelukkende nydelsen. Analyse er noget, dex ex opfundet 09 praktiseres af padagoger.

Netop spørgsmalet om analyse og analysemetoder er meget relevant i forhold til musikvideoex. Det er ikke muligt, at analysere musikvideoer efter de, for filmanalytikere, så sadvanlige metoder. Der er en markant tendens til at musikvideoex (bestente TV-serier, film som Diva, Subway og Highlardersl bevager sig bort fra fortalingen. Fortallingen/handingen hax inden for filmediet varet bygget op efter fastlagte fortallestrukturer (f.eks. den dramatiske kurve). Denne form for fortaling ex pa retur i flew re af de nye medieudtryk.

Musikvideoerne er saledes uatryk for brud pa de traditionelle fortallemassige koder. Dette galder ikke kun fortalingen, men ogsa de formmsige forhola. 
Musikvideoernes sprog

Musikvideoeme bryder forst og fremmest med den traditionelle filmkunsts kontinuitetsprincipper. Kontinuitet i kamerabevagelser, lydmassige overgange, blikretning motiveret klipning, bevidste fors $\phi g$ på at skjule klipningen arbejder de fleste musikvideoer direkte imod. Man kan sige, at diskontinuiteten er fremherskende - desto flere chokerende brud desto bedre. Der ex derfor 1 musikvideoerne heller ikke tale om enhed i tid, rum og handling.

Afgфrende for oplevelsen er ogsa, at skuespiller/stjernesystemet er 1 opbrud, idet musikgruppen og $i$ sardeleshed forsangeren ma agere og spille skuespil. Dette er der selvfolgelig kommet nye stjerner ud af $\mathrm{f}$.eks. Duran Duran, som har varet meget bevidst on både balledbrug og selviscenesattelse i deres videoex.

Musikvideoens brudte struktur understreges yderligere af fanomenet "Ideas pr. minute", som man opererer med i produktionsfasen. Malet ex sa mange indfald, skpre ideer, flotte billeder m.v. som muligt, og ikke en konsekvens 1 brugen af virkemidler - det er med andre ord virkemidler for virkemialernes skyld.

Dette hanger bl.a. sammen med, at producenterne ved, at publikum kan lase billeder. Det ex derfor muligt at lave meget "komprimerede" billeder. Endelig er det jo ogsă tanken, at en musikvideo skal ses flere gange, hvorved der bliver mulighed for at se og opfatte de billeder, man ikke flk set de forste gange.

Musikvideoerne har ogsa medvirket til udvikling af nye teknikker - f.eks. stopanimation og grafik. Ved stopanimation speedes filmen op, og man klipper billeder ud, hvilket bevirker, at alt bevages hurtigt og afrupt. Netop denne teknik understreger videoernes brudfyldte struktur. Grafikken laves på computer - og er ret bekostelig. Et par af de smukkeste eksempler på grafik anvendt i videoex ex nok Mick Jaggers Hard Woman og Dire Straits Money for Nothing. 


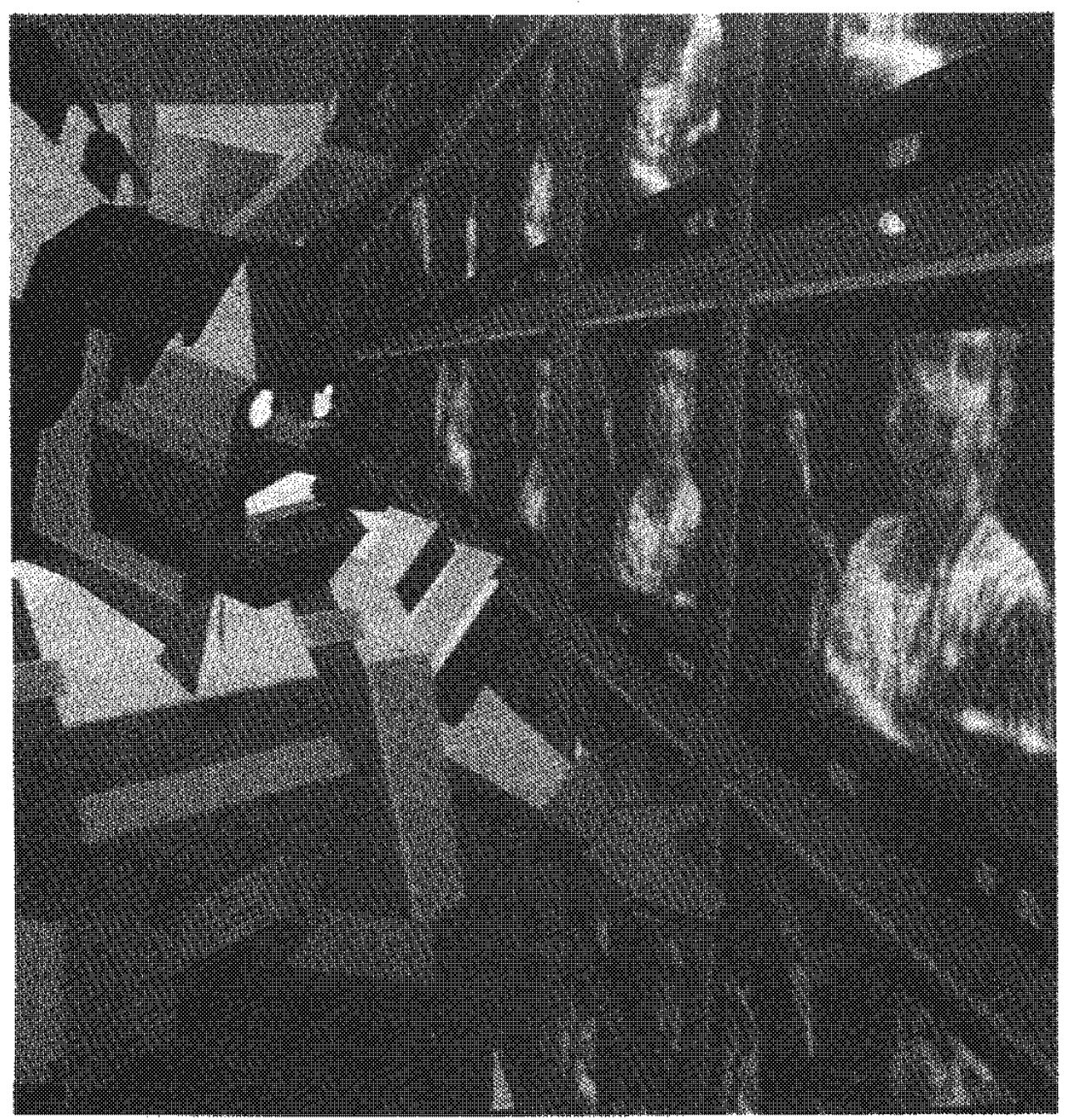

\section{Dire Straits Money for Nothing}

Den kontrakt der indgas med tilskueren er meget anderledes for musikvideoernes vedkommende end for de klassiske spillefilm. Endringen i oplevelsesmonstre kan bl. a. forklares i ænaringen $i$ socialisationsstrukturen.

De unge ex abne overfor nye ind-og udtryk, de hax en her-og-nuindstillet beviasthed, og de er konstant pe jagt efter nye oplevelser, hvilket ovenstaende citat fra Levende billeder vidner om. Musikvideoerne har kunnet tilfredsstille nogie af de behov, som den narcissistisk orienteret ungdomssocialisation har skabt. 
De unges oplevelsesstrukturer og f.eks. musikvideoernes fortalleteknik passer godt sammen, eftersom musikvideoerne kan frisætte en rakke associationer, fantasier og drome. De mange billedmassigt skфre pahit bevirker, at den rationelle bevidsthed sættes ud af kraft, og tilskueren trakkes med i en strom af lystEylate associationer.

\section{Et undervisningsforlgb i billeder og musik}

Da jeg, som over for beskrevet, ikke kunne begejstre mine elever til at beskeftige sig udelukkende med musikvideoer, fandt vi frem til et forl $\phi b$ om musik og billeder. Forl tbet havde fфlgende hovedpunkter:

1. Koncertoptagelsexs udvikling (vist på TV)

2. Musikvideoer, kategorisering, estetik, formmasige forhold

3. Art videos

4. Selvproducerede musikvideoer eller art videos.

Ideen til forlobet fik jeg, da vi havde set Prince i Purple Rain. Det var kort tid efter en koncertoptagelse i TV med Prince and The Revolution.

Forskellen mellem film og koncertoptagelse er ens, som man siger - eller sagt pă en anden made Purple Rain handler udelukkende om prince og hans musik, selvom filmen dramatisk ex bygget op om en karlighed- og familiehistorie.

Săvel i filmen som i koncextoptagelsen salger Prince, med sit underliv, en rä seksualitet, hvilket kan ses helt ned i billedperspektiverne. Backinggruppen The Revolution er blot en nodvenaighed for iscenesattelsen af Prince i film som i koncertoptagelse.

Det kan sikkert ikke undre, at billedsprog, klipning, lys og røgudadninger i koncertoptagelser har andret sig betydeligt de seneste år. I koncertforlфb laves der fiktive forlob f.eks. en sekvens, hvor Tina Turner skifter t $\phi j$, for at salge sin seksualitet via flotte 50'årige ben, inden samspillet med en mandig 
kollega. Eller Duran Duran der har koncertforlob og forskellige billedsekvenser kørende pa store videoskeme ved siden af selve koncerten. Fiktion og "virkelighed" blandes konstant sammen i disse nye billedformer. Det er utvivlsomt musikvideosproget, der har virket ind på denne hurtigere og "frakkere" måde at lave koncertoptagelsex på.

Det er relativt let at fa fat 1 koncertoptagelser, idet "de store navne" ofte laver koncerter med henblik pa TV. Det er salledes min erfaring, at det er godt at sammenligne koncertoptagelser, nye som gamle, med musikvideoer og film, der er meget baseret pa musik. Der er basis for at vise disse mediers indbyrdes afsmitning billed-og fortallemasigt.

\section{Kategorisering af musikvideoer}

Fra disse koncertoptagelsex ex dex ikke langt til Marsha Kinders forste kategori af musikvideoer. Marsha Kinder indaeler $i$ artiklen "Music Video and the Spectator" (Film Quarterly Fall 1984) musikvideoerne $i$ føigende kategoxier:

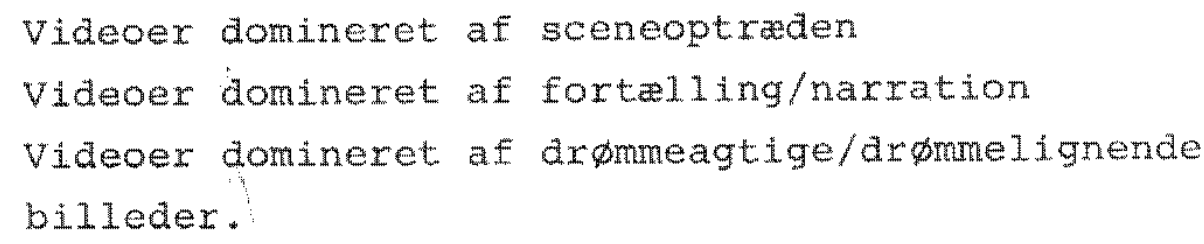

Kinder skriver 1 sin artikel, at dex ex tale om domineret af.... idet det er sjwldent, at en musikvideo er udelukkende sceneoptraden, fortaling elir dromeagtige billeder.

\section{Musikvideoer domineret af sceneoptraden}

Videoer domineret af optraden er langt den storste gruppe. Herhjemme ser vi kun de gode videoer, men hvis man kan tage udenlandske kanaler vil man erfare, at musik-videoer ikke altid er flot billedkunst.

Et stort antal videoer er bade pa billed-og lydsiden domineret af sceneoptraden, men de fleste af disse har ogsa afbrydelser af 
optraden f.eks. en lille historie eller visuelle indskud. Disse afbrydelser vil ofte tage udgangspunkt i hookline (melodiens refrain). De fleste musikvideoex er opbygget pa den măde, at dex er en lille instroduktion uden musik inden "selve" videoen starter. I denne introduktion anslås en steming eller en lille historie f.eks. i Beast of Burden, hvor Bette Midier har byttet en sheik ud med M. Jagger. I denne video, der er ren optraden, kippes sheiken ind et par gange umotiveret, idet tekstsiden ikke navrer ham, men vi kendex ham fra introduktionen.

Dammarks Radio klipper introduktioneme fra, idet der oftest reklamres i disse for pladen ved hjwlp af coveret. Det er karakteristisk for denne type videoer, at dex klippes hurtigt - tank blot pa whams wake me up before you gogo, hor der skiftes tфj, position, billedperspektiv og klippemade konstant i en video

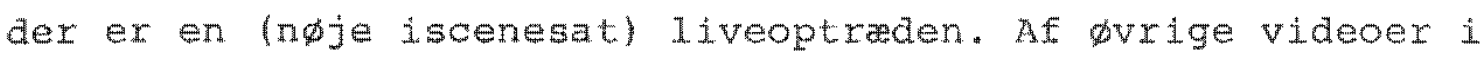
denne kategori kari navnes omtalte Beast of Burden, U B 40's I got you Babe og ikke mindst Springsteen/de palmas Dancing in the Dark.

\section{Videoer domineret af narration}

I sin mest ekstxeme form kan denne type musikvideoer fa karakter af "mini-film", hvor fortalingen bade dominerer sangen og billederne - og hvor billederne iliustrexer sangens indhold.

Der ex eksempler på musikvideoer i alle traditionelle filmgenre ganster-, horror-, tegne- og film noir-film. Der trakkes således pă filmkunsten som på et stort billedmuseum. Det er jo ogsă en kendt sag, at der ex delte meninger blandt "rigtige" filminstruktorer om musikvideoernes betyaning for filmbilledsprogets udvikling. Der er flere instruktoxer, de Palma og Fellini for blot at nevne et par stykker, der har provet krafter med det nye medie.

Nar de fortallende videoer ikke benytter sig af traditionelle genrekonventioner ex det almindeligt, at de kun er i besiddelse 
af en tyndt fortallemassig rod tråd. Denne svage rode tråd iscenesetter som reglen en grundlaggende erotisk fantasi/en erotisk situation, som seeren alt efter smag og kon kan bygge videre pa.

Manglerne på struktur og handlingsmassig fremdrift i disse videoer udfyldes ofte med eksotiske scenerier, kostumer, koreografi, hurtige klip, elektroniske og фvrige visuelle effekter. I de narrative videoer vil stjernen/sangeren oftest, 1 stedet for at optrade på scenen, spille en hovedrolle $i$ historien og mime sangen. De $\phi v r i g e$ musikere brillierer ved deres fravar. Der ex selvfфlgelig en fidus, at gruppen/solisten ses 1 videoen for at man kan genkende den/vedkommende, năr man stăr med coveret i handen. I ovrigt bruges billeder fra videoen ogsa til pladecoverets forside.

Af videoer i denne kategori kan nevnes: Cars" Hello again (1avet af Warhol), 2Z Top's Legs, Kinks" Come dancing, Mick Jaggers Hard Woman.

\section{Videoer domineret af axprmeagtige billeder}

Denne type videoer intenderer at vare drommebilleder eller drommeagtige billeder. Videoerne tager udgangspunkt i såvel nattedrommens ubeviaste eller fortrangte materialer som i dagarommens mere bevidste fors $\phi \mathrm{g}$ p lystbetonet behovstilfredsstillelse. VI bevager os ud 1 det ukendte og ubeviaste. Her oplöses tia, rum, handling og årsagssammenhange. De sadvanlige normer, lkke mindst de seksuelle, overskrides konstant. Der er i disse videoer mulighed for, at tilskueren kan koble sine exotiske fantasier, tabuer og lystex pa.. Videoemes emner ex i overvejende grad vold, angst, seksuelle stimuli og seksuelle pervertioner. Musikken bliver et akkompagnement til fantasifyldte billeder.

Det er især denne type videoer, der gфr den rigeste brug af mediet. Interessen for at antyde, satte associationer i gang bruges på alle mulige mader. Musikere med udgangspunkt i billedkunsten f.eks. Davis Burne fra Talking Heads eksperimenterer med 
billedmediet på en måde, der giver mindelser om avantgarde- og eksperimental-filmen. Det er ogsa karakteristisk for denne kategori af videoer, at fortallersynsvinklen ofte andres - f.eks. mellem objektivt og subjektivt kamera. Denne andring $i$ fortallesynsvinkel ex bl.a. en konsekvens af ophavelsen af kontinuiteten $i$ handing og klipning. Omtalte strukturering af videoerne bevirker, at tilskueren placeres i en bevidsthedstilstand, der ligm ner eller kan sammenlignes med dromens.

Tilskueren kan valge synsvinkel, og kan derfor valge at placere sig der, hvor lystgevinsten ex storst. Nar man ser pa musikvideoex f.eks., er der tale om erstatningstilfredsstillelse. His man ikke far opfyldt sine behov 1 hverdagen, kan man ty til de fascinerende musikvideoer, hvor seksuelle fantasier og dagdromme bankes ud. De videoer, vi har arbejdet med indenfor denne gruppe er Selfcontrol med Laura Brannigan, Wild Boys med Duran Duran, And she says med Talking Heads og owner of a lonely Heart med Yes.

Ronkluderende på dette musikvideoafsnit kan man sige, at musik"videoernes fortalleform med opsplittede, oftest ikke eplske historier, knytter an til publikums ojebliksorienterede opmarksomhedsstruktur. Det er ikke muligt at fatte alt, bade fordi billederne ikke altid har en indbyrdes relation, og fordi TV-mediet lkke appellerer til 100\% koncentration. Dette bevirker bl.a., at musikvideoerne kobler an til de unges ubevidste, til deres dromme og onsker.

\section{Art videos}

Efter ovenstaende arbejde med musikvideoerne har vi afslutringsvis set et par axt videos, dels fordi det ex en relativt ny udtryksform i Danmark, dels fordi mange art videos kombinerer musik og billeder. En tredje, og pedagogisk, begrundelse er, at mange art videos ex lavet med relativt enkle midier, hvilket kan vare et eksempel for elevernes eget arbejde. Flere af de axt videos, vi har set, har varet koncentreret om en enkel, men god ide. 
Jeg har brugt de art videos, der har varet i DR bl.a. i programm mer med Poul Borum. Jeg har haft gode erfaringer med at vise Max Anys Leaving the 20"th Century, som i sin teknik ikke er enkel, skal siges.

Art videoen starter med, at en person, der ligger og sover, skal vakkes. Pexsonens dromme inden han vakkes, ex et hidsigt sammenklip af amerikansk TV. Art videoen handler videre om vanskeligheder ved at forholde sig til og tilpasse sig omverdenen og om komminationsstrukturex. Leaving the $20^{\circ}$ th century har givet mange gode diskussioner om mediebevidsthed, amerikansk IV, de unges medieforbrug osv.

Jeg syres, at musikvideoen og art videoen er gode "genre" at bruge til praktisk mediearbejde, idet de pga. langden er overskuelige projekter. Trods lidt spredte erfaringer, tror jeg nok, at jeg vil konkludere, at det ex mest motiverende, hvis eleverne selv bestemmer musikken til musikvideoen.

Ovenstaende forlob har 1 overvejende grad varet bygget op om musikvideoer - trods elevernes unidaelbare uvilje mod at beskaftige $\mathbf{s i g}$ med dem. Nar jeg alligevel har fundet det vasentigt at arbejde med videoerne, skyldes det ikke mindst astetikken og formsproget. Jeg mener, at det er med til at skxpe mediebevidstheden, hvis man kan analysere andringer i billedsproget og diskutere disse andringers betydning for vores billedperception.

\section{LITTERATUR}

"Analyser af TV" red. Ralf Pittelkow. Medusa 1985

"Musik Video and the Spectator" Marsha Kinder in Film Quarteriy Fall 1984

"sing a song of Seeing" in Time Magazine 52, 1983

"Hinsides fortalingen" Peter Larsen in Argos nr. 3

"Musik Video Madness" peter Larsen in Information 21-22/7 84

"ZzZAAApP.. Zig Zag- Transmissionex fra et beruset IV-apparat" in Ungdons kultur Forskningsrapport 1985, Borgen red. Joi Bay

"Rockvideoens scenemagikere" Benny Bang Carlsen upubliseret

"Rockvideo med ny symbolverden", Lasse Ellegaard in Samvirke, feb. 1985.

"Art-video - en kunst på skarmen" Carl Norrested in Kosmorama nr. 178, vinter 86 Levende billeder nr. 9 dec. 1986

Rarin Jacobsen er ansat på Marselisborg Gymasium 


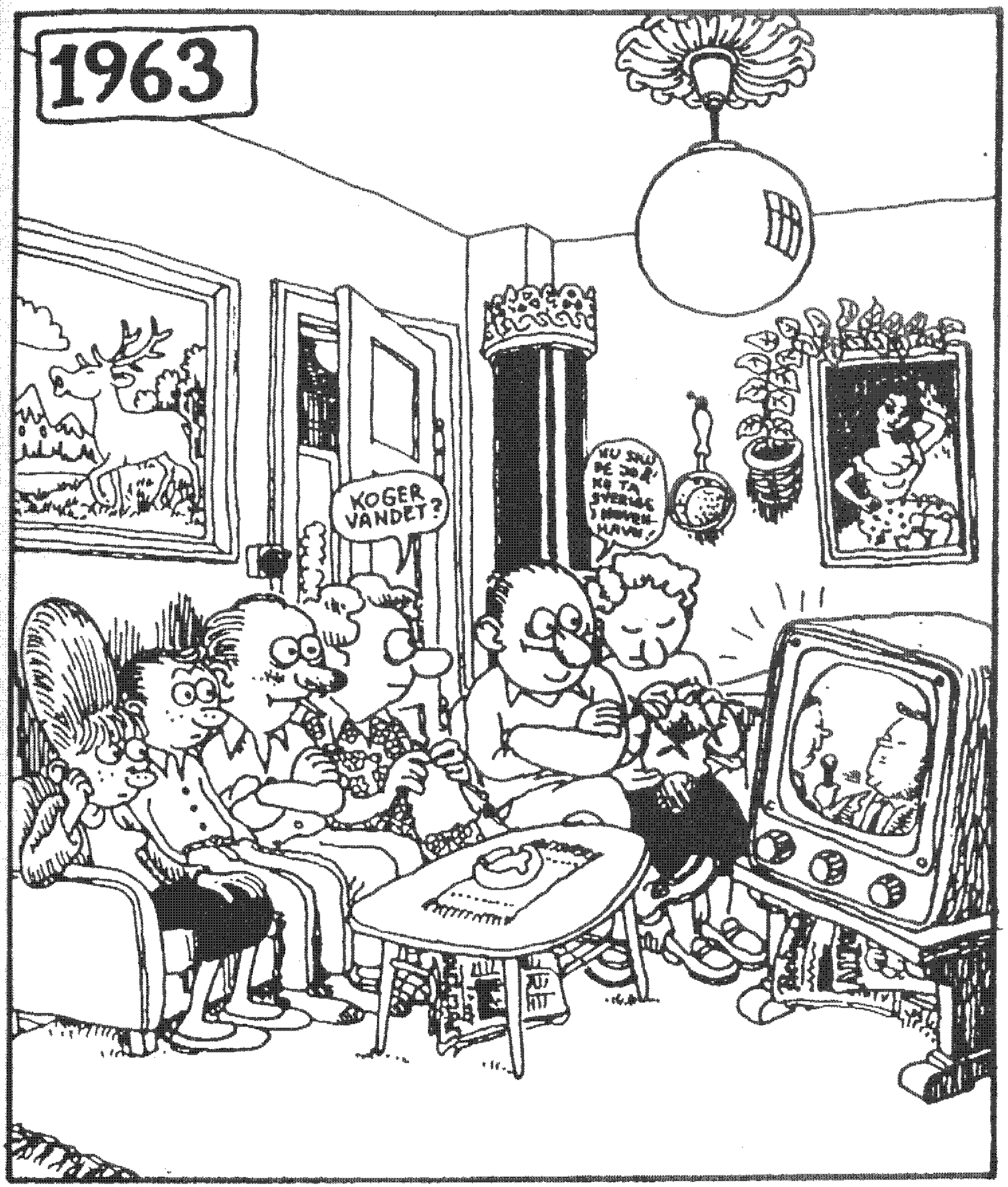

